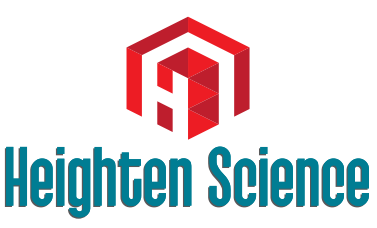

P U B L I C A T I O N S Corporation

\title{
Demographic survey and
} management outcome of PostNeonatal Tetanus at the Ekiti state university teaching hospital, Ado Ekiti

\author{
Ajite $\mathrm{AB}^{1 *}$, Ogundare $\mathrm{EO}^{1}$, Oluwayemi $10^{1}$, Olatunya $\mathrm{OS}^{1}$, \\ Babatola $A^{1}$, Taiwo $A^{2}$, Komolafe $A^{2}$ and Fatunla $0^{2}$ \\ 'Department of Paediatrics, Faculty of Clinical Sciences, College of Medicine, Ekiti State \\ University, Ado Ekiti, Nigeria \\ ${ }^{2}$ Department of Paediatrics, Ekiti State University Teaching Hospital, Ado Ekiti, Nigeria
}

\begin{abstract}
*Address for Correspondence: Dr. Adebukola Ajite, Department of Paediatrics, Faculty of Clinical Sciences, College of Medicine, Ekiti State University, Ado Ekiti, Nigeria, Tel +2348069712558; Email: bidemi_kayode@yahoo.com
\end{abstract}

Submitted: 01 April 2019

Approved: 22 April 2019

Published: 23 April 2019

Copyright: (c) 2019 Ajite AB, et al. This is an open access article distributed under the Creative Commons Attribution License, which permits unrestricted use, distribution, and reproduction in any medium, provided the original work is properly cited

Check for updates

\section{Abstract}

Background: Tetanus continues to threaten the survival of children in spite of it being a vaccine preventable disease. The objective of this study was to determine the prevalence of post-neonatal tetanus, review the vaccination of affected children, complications encountered and the outcome among affected children in a tertiary health institution in southwestern Nigeria.

Methods: The study was a retrospective study. Case notes of children outside neonatal life admitted to the Paediatric ward with clinical diagnosis of tetanus between January 2012 and October 2018 were retrieved and evaluated to identify socio-demographic and clinical characteristics. A review of the immunization history and cards was done where the immunization cards were available.

Results: 21 children with post-neonatal tetanus were admitted over a period of six years (November 2012 to October 2018) with a prevalence of $0.3 \%$. The M:F was 3.2:1. The mean age in years was $10.14 \pm 3.44$ while the age range of the subjects was 4 to $16 y e a r s$. None of the patients had booster doses of tetanus toxoid (TT) outside the infancy period. Nine $(42.9 \%)$ subjects had no previous TT vaccination, 2 (9.5\%) had 3 doses of TT vaccine in infancy but developed tetanus at age $\geq 9$ years, $1(4.8 \%)$ subject had a dose of TT while the remaining 9 subjects had no proof of previous TT vaccination. The percentage mortality was $19 \%$ (4 out of 21 ). All the patients that died had no prior record of TT vaccination. Complications identified included laryngeal spasm and autonomic dysfunction.

Conclusion: Post-neonatal tetanus is still common in our locality because booster doses of Tetanus Toxoid are not part of the national immunization schedule. Complete dose of tetanus toxoid vaccination during infancy and booster doses at school entry is necessary and should be part of school health programme to forestall post-neonatal tetanus.

\section{Introduction}

Tetanus is caused by the neurotoxin produced by Clostridium tetani, a grampositive, motile, spore-forming bacillus. The organism is an obligate anaerobe [1]. Infection usually follows contamination of a wound by soil containing spores of the organism from animal manure [2]. It is a vaccine preventable disease. According to the World Health Organization (WHO), a childhood immunization schedule of five doses is recommended. The primary series of three doses of tetanus toxoid vaccine should be given in infancy. WHO recommends that the 3 booster doses should preferably be given during the second year of life (12-23 months), at 4-7 years, and at 9-15 years of age with at least 4 years between booster doses [3]. The completion of 6 doses of TT 
containing vaccine is expected to provide protective antibody levels of $\geq 0.01 \mathrm{IU} / \mathrm{ml}$ for 20 to 30 years [4,5]. This is expected to forestall the occurrence of post-neonatal tetanus.

Unimmunized or incompletely immunized individuals are at risk of developing tetanus [2]. Mothers in south western part of Nigeria erroneously refer to the vaccine received at the $9^{\text {th }}$ month of a child's life as "MOYEGE" meaning that "I am through with the immunization schedule" and so do not present for booster doses of TT or are not aware of the need for booster doses. A previous study done in south west Nigeria showed the prevalence of post neonatal tetanus to be $0.6 \%$ of the total admission over 3 years. i.e. January 2011 and December 2013 [6]. A study by Adegboye et al. [7], over a three-year period (April 2008 - March 2011) showed that 70 of the 95 children with childhood tetanus at the University Teaching Hospital Ilorin, Nigeria had neonatal tetanus while the remaining 15 patients had post-neonatal tetanus. This puts the prevalence of post-neonatal tetanus to be $0.4 \%$ of the 3880 children admitted over the study period. The case fatality rate of tetanus in their study was $62.1 \%$ [7]. A study of childhood tetanus in post-neonatal age group in Delhi by Mondal et al., showed that all the 55 patients with post-neonatal tetanus between January, 1989 and June, 1991 except one were either unimmunized or incompletely immunized [8].

The incidence and mortality due to tetanus in the United States were reported to have declined at a constant rate since the early $1900 \mathrm{~s}^{9}$. The factors responsible for this have been attributed to the widespread coverage of tetanus toxoid vaccine, improved wound care and post-exposure use of tetanus immune globulin among others $[9,10]$.

It has been predicted that tetanus will continue to be a Paediatric problem until vaccination strategies are effectively implemented and surveillance systems are strengthened [11]. There has been an increase awareness and improvement in immunization coverage over the years, however, there is need to do more so as to achieve tetanus eradication. The objectives of this study were to assess the current prevalence of post-neonatal tetanus, review the vaccination of children with postneonatal tetanus, the co- morbidity, complications and relate the vaccination status to the outcome of such in a tertiary health institution in southwestern Nigeria.

\section{Method}

The study was a retrospective descriptive cross sectional study. Ethical clearance was obtained from the Research and Ethics Committee of Ekiti State University Teaching Hospital, Ado Ekiti. Tetanus case definition was taken as an acute illness with muscle spasms or hypertonia in the absence of a more likely diagnosis, and diagnosis of tetanus by a health care provider; or death, with tetanus listed on the death certificate as the cause of death or a significant condition contributing to death [12]. Case notes of post neonatal children admitted to the Paediatric ward with clinical diagnosis of tetanus between January 2012 and October 2018 were retrieved and evaluated to identify socio-demographic and clinical characteristics of the affected children. These included the age, gender, address, highest level of formal education and occupation of parents, tribe, average monthly income of parents/caregivers, details of antenatal history of mother and review of the immunization history were done. The patients were assigned to social groups using the level of formal educational attainment and occupation of the parents as described by Oyedeji et al. [13]. The presenting complaints, possible focus of infection, incubation period and period of onset, duration of admission, co-morbid conditions and complications as well as the outcome were extracted from the case notes.

Data analysis

Data analysis was done using Statistical Package for Social Sciences (SPSS) version 20. Descriptive statistics comprising of mean, standard deviation, percentages and 
proportions were used as well as comparative statistics. A $p$ value of 0.05 or less was considered to be statistically significant.

\section{Results}

A total of 21 children with post-neonatal tetanus were admitted during the study period. The M:F was 3.2:1. Figure 1 shows the gender distribution of the patients.

The mean age in years was $10.14 \pm 3.44$ while the age range of the subjects was 4 to 16years. Figure 2 shows the frequency of occurrence of post neonatal tetanus among children under five years of age and school aged children.

The prevalence of post neonatal tetanus was $0.3 \%$ of the 7028 children admitted over this period. Table 1 shows the pattern of immunization of the patients.

None of the patients had booster doses of TT outside infancy period. Nine (42.9\%) of the subjects had no TT vaccine in infancy, $2(9.5 \%)$ had 3 doses TT vaccine in infancy but developed tetanus at age $\geq 9$ years, $1(4.8 \%)$ had a dose of TT while the tetanus immunization status of the remaining 9subjects was uncertain.

All the patients were from families of low socio-economic class using the proforma of Oyedeji et al. [13]. Mothers of five of them had no antenatal care and TT vaccine and there was paucity of information on the immunization status of the remaining 16 mothers. Places of delivery of these patients included; primary health care facilities and mission houses. The portal of entry was not known in one (4.8\%) of the patients while in the others the leading focus was punctured wound and bruises sustained on the lower extremities 19(90.4\%), only one patient had otitis media as the likely portal of entry. The frequency of presenting complaint is shown in table 2 while the outcome of the admission is illustrated by table 3 .

There was no statistically significant difference in the outcome of post-neonatal tetanus between pre-school and school age children, the Fisher's exact value was 1.000 ( $\mathrm{p}=0.569)$, Phi value was $0.115(\mathrm{p}=0.599)$.

The co-morbidities and complications identified in the patients included two patients with fever, four of them had evidence of urine retention and profuse sweating and there was a case of laryngeal spasm. The patients were treated with anti-tetanus serum (ATS), parenteral diazepam, phenobarbitone, chlorpromazine and metronidazole while antibiotic (mainly cefuroxime) was administered for those presenting with fever. At discharge the patients were given tetanus toxoid and were followed up in the clinic.

Table 4 shows the mean values and the range of duration of admission, period of onset and incubation period. There was no statistically significant correlation among these variables in the patients as shown in table 5.

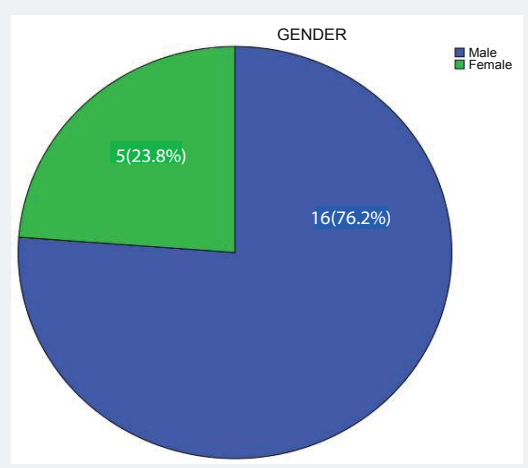

Figure 1: Gender distribution of the subjects. 


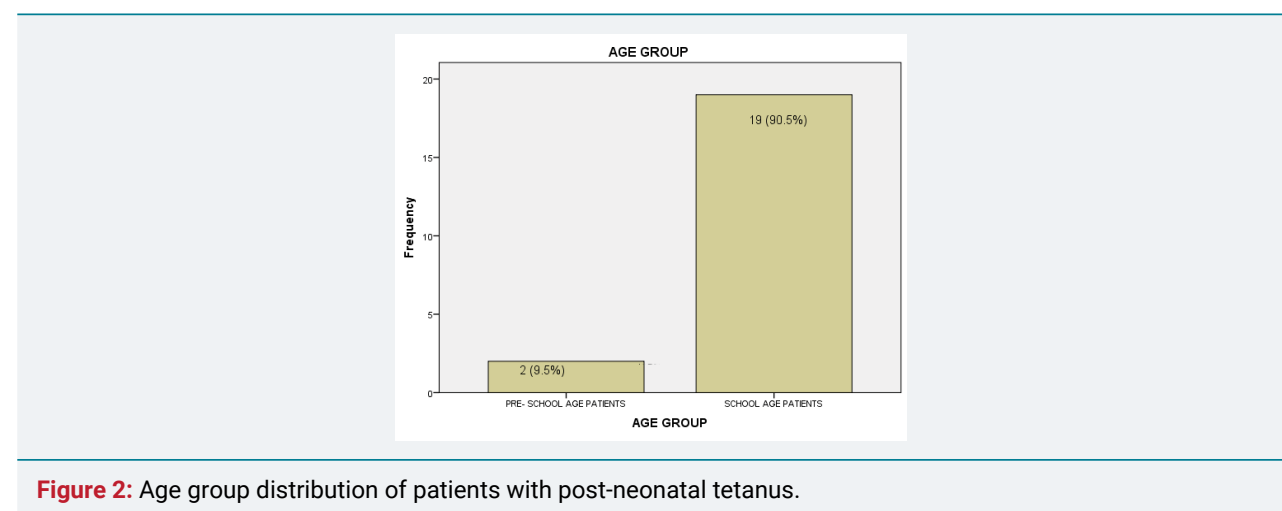

Figure 2: Age group distribution of patients with post-neonatal tetanus.

Table 1: Pattern of immunization of the subjects.

\begin{tabular}{|c|c|c|c|c|c|}
\hline \multirow{2}{*}{ Age (years) } & Pad 3 doses of TT in infancy & Had no TT & Uncertain & Had 2 doses of TT In infancy & Total \\
\hline 4.00 & 0 & 1 & 0 & 1 & 2 \\
\hline 7.00 & 0 & 2 & 1 & 0 & 3 \\
\hline 8.00 & 0 & 1 & 1 & 0 & 2 \\
\hline 9.00 & 1 & 0 & 1 & 0 & 2 \\
\hline 10.00 & 0 & 1 & 2 & 0 & 3 \\
\hline 11.00 & 1 & 0 & 1 & 0 & 2 \\
\hline 12.00 & 0 & 0 & 2 & 0 & 2 \\
\hline 14.00 & 0 & 2 & 0 & 0 & 2 \\
\hline 15.00 & 0 & 0 & 1 & 0 & 1 \\
\hline 16.00 & 0 & 9 & 9 & 1 & 21 \\
\hline Total & 2 & & & & \\
\hline
\end{tabular}

Table 2: Frequency of Presenting Clinical Features.

\begin{tabular}{|c|c|}
\hline Presenting signs and symptoms & Frequency (\%) \\
\hline fever, lock jaw, spasm & $5(23.8 \%)$ \\
\hline lock jaw, spasm & $4(19.0 \%)$ \\
\hline fever, spasm & $1(4.8 \%)$ \\
\hline lock jaw, spasm, ear discharge & $1(4.8 \%)$ \\
\hline spasm and rigidity & $9(42.9 \%)$ \\
\hline spasm, lock jaw, opisthotonus position, & $1(4.8 \%)$ \\
\hline Total & $21(100 \%)$ \\
\hline
\end{tabular}

Table 3: Outcome of patients with post-neonatal tetanus.

\begin{tabular}{|c|c|}
\hline Table 3: Outcome of patients with post-neonatal tetanus. & Frequency \\
\hline Outcome & $14(66.7 \%)$ \\
\hline Discharged & $3(14.3 \%)$ \\
\hline LAMA & $4(19.0 \%)$ \\
\hline Died & $21(100.0 \%)$ \\
\hline Total & \\
\hline LAMA- left against medical advice.
\end{tabular}

Table 4: Duration of admission, period of onset and incubation period.

\begin{tabular}{|c|c|c|c|}
\hline & Minimum & Maximum & Mean \pm standard deviation \\
\hline Incubation period in days & 2.00 & 28.00 & $12.75 \pm 7.83$ \\
\hline Duration of admission in days & 1.00 & 30.00 & $13.61 \pm 8.10$ \\
\hline Period of onset in hours & 2.00 & 72.00 & $28.50 \pm 20.06$ \\
\hline
\end{tabular}

Table 5: Correlations of Incubation Period, Period of Onset and Duration of Admission.

Correlations

\begin{tabular}{|c|c|c|c|c|}
\hline \multirow{2}{*}{ Period of onset (hours) } & $\begin{array}{c}\text { Period of onset } \\
\text { (hours) }\end{array}$ & $\begin{array}{c}\text { Duration of } \\
\text { admission (days) }\end{array}$ & $\begin{array}{c}\text { Incubation period } \\
\text { (days) }\end{array}$ \\
\hline \multirow{2}{*}{ Duration of admission (days) } & Pearson Correlation & 1 & & \\
\cline { 2 - 5 } & Sig. (2-tailed) & & & \\
\cline { 2 - 5 } & Pearson Correlation & .040 & 1 & \\
\hline \multirow{2}{*}{ Incubation period (days) } & Sig. (2-tailed) & .903 & .251 & 1 \\
\hline & Pearson Correlation & .324 & .431 & \\
\hline
\end{tabular}




\section{Discussion}

Post-neonatal tetanus continues to be a health challenge among children in the developing world. The prevalence of post-neonatal tetanus in the index study is $0.3 \%$. This is lower than the previous prevalences of $0.6 \%$ reported by Animasahun et al. [6], in Lagos (2011-2013), 1.8\% by Oyedeji et al. [14], in Ilesha (2012), 1.1\% by Anah [15] in Calabar (1997-2006) and $1.4 \%$ by Alhaji et al. [16], in Maiduguri (2009-2011). This declining prevalence could be attributed to the improvement in immunization coverage, health education as well as improved approach to the care of wound and hygiene in the society which is brought about by increased civilization.

There was male preponderance with male to female ratio of 3.2:1 in the index study. Similar reports were noted in earlier studies [14-17] and this has been attributed to the adventurous nature of the male gender with tendency to have injury that may be infected. These children also tend to hide their wounds from the parents because of the fear of being reprimanded.

The patients with post-neonatal tetanus in the index study were within the age range of 4-16years with the mean age of 10.14 \pm 3.44 years. Post-neonatal tetanus had been reported in children younger than 4years in previous studies $[15,16]$. These studies $[15,16]$ were over a decade ago hence, the improvement in accessing health care services and increased coverage of routine childhood immunization over time may account for this. Nevertheless, two patients in the index study who completed the 3 doses of tetanus toxoid given as part of routine immunization in infancy developed tetanus at age's $\geq 9$ years. Also, $19(90.5 \%)$ cases were of ages greater than 5 years and none of the patients had booster doses of TT. These observations suggest that there is greater risk of post-neonatal tetanus the further away the child is from the last immunization and this is in line with previous documentation that the protective level of antibody given by three doses of Tetanus Toxoid lasts for about 3-4 years [18]. Therefore, the 3 doses of TT administered in infancy according to the National Program on Immunization (NPI) schedule in Nigeria may not be sufficient to ensure that a child is totally free of post-neonatal tetanus as he/she grows older. Nineteen (90.5\%) were of ages greater than 5 years and none of the patients had booster doses of tetanus toxoid. This suggests that booster doses of TT are necessary. Hence, there is a need to further expand the present immunization schedule to incorporate booster doses of TT so as to forestall the occurrence of this vaccine preventable disease among school age children. More so, it was reported that the protective immunity of tetanus toxoid received in infancy wanes over time [19]. Similarly in Tanzania, Aboud et al. [20], reported low levels of protective neutralizing antibodies to tetanus among children aged 6-15 years after routine immunization in infancy.

Ten of the patients either had no TT in infancy or were incompletely vaccinated in infancy while nine were not certain of having been vaccinated in infancy. Incomplete vaccination and non-vaccination are common occurrences in post neonatal tetanus. This similar finding had been earlier documented by Yaguo et al. [21], thus raising the need to intensify efforts at enhancing compliance with the current national immunization schedules in Nigeria.

That all the patients in the index study were from the low social class is in conformity with earlier studies where patients with post-neonatal tetanus were majorly from the low social class $[15,16]$. The occurrence of post-neonatal tetanus appears to commonly affect people from the low socio-economic class who are likely to have environment with poor hygiene, poor health seeking attitude and be ignorant. Therefore the vicious circle of poverty, ignorance and disease serves as a risk factor.

The symptoms that most of the patients presented with were spasm and rigidity while the most common portal of entry was wound on the lower limb. This is similar to 
findings from previous studies $[6,15,16,22,23]$. It becomes imperative that health care workers should endeavor to take immunization history while attending to children with injury/injuries sustained on the limbs and vaccinate appropriately.

There is prolonged duration of hospital stay in this study with the mean duration of $13.61 \pm 8.10$ days. Similar finding has been reported by Animasahun et al. [6] in Lagos and Alhaji et al. [16] in Maiduguri. This is due to the natural course of tetanus in which the symptoms are pronounced in the first week, reach a plateau in the second week and begins to improve by the $3^{\text {rd }}$ week. This has a lot of financial implication for parents who in most instances are poor and have to pay out of pocket. It has also contributed to making some of them leave the hospital against medical advice.

The complication and co-morbidity recorded in the index study included laryngeal spasm and acute urine retention. A study done in Lagos ${ }^{6}$ recorded acute kidney injury as a complication seen in post neonatal tetanus while Alhaji [16] in Maiduguri reported bronchopneumonia. There appears to be a diversity of complications that may occur in post-neonatal tetanus.

The incubation period and period of onset have no statistically significant correlation with the clinical outcome of patient with post neonatal tetanus in the index study unlike what has been reported in neonatal tetanus [24]. A similar observation was made by Anah et al. [15] in Calabar. The incubation period and period of onset may not be useful tools in post-neonatal tetanus to determine the prognosis. Further studies preferably a prospective study may unravel other factors that may play significant roles in the outcome of patients with post-neonatal tetanus.

The mortality rate was $19 \%$ in this study which is similar to $18 \%$ reported in Calabar [15] and Maiduguri [16] but higher than 4.1\% reported by Animasahun et al. in Lagos [6]. The lower value in Lagos was explained by the availability of free health during the period of the study which made accessing health care less difficult. Reports from earlier researchers $[6,15,16,21,25]$ on post neonatal tetanus had all pointed to the need for booster doses of tetanus toxoid in children; this is further re-iterated by the findings of the index study.

\section{Conclusion}

Post-neonatal tetanus remains a problem of Nigerian children primarily because booster doses of Tetanus Toxoid are not included in the national immunization schedule. It is time to yield to earlier calls for booster doses of Tetanus Toxoid to keep our children safe and reduce childhood morbidity and mortality due to this vaccine preventable disease.

\section{References}

1. Aron SS. Tetanus (Clostridium tetani); Nelson Textbook of Pediatrics. Berman RE, Kliegman RM, Jenson HB, Stanton BF. 18th ed. Philadephia, 2007; Ref.: https://tinyurl.com/y5tpobpq

2. Brook I. Current concepts in the management of Clostridium tetani infection. Expert Rev Anti Infect Ther. 2008; 6: 327-336. Ref.: https://tinyurl.com/y5otqum9

3. WHO. TETANUS. 2018; Ref.: https://tinyurl.com/y5jeph9o

4. Gonçalves G, Santos MA, Frade JG, Cunha JS. Levels of diphtheria and tetanus specific IgG of Portuguese adult women, before and after vaccination with adult type Td. Duration of immunity following vaccination. BMC Public Health. 2007; 7: 109. Ref.: https://tinyurl.com/yxv4fxkb

5. Ölander RM, Auranen K, Härkänen T, Leino T. High tetanus and diphtheria antitoxin concentrations in Finnish adults; Time for new booster recommendations? Vaccine. 2009; 27: 5295-8298. Ref.: https://tinyurl.com/y6ch2t87

6. Animasahun BA, Gbelee $\mathrm{OH}$, Ogunlana AT, Njokanma OF, Odusanya O. Profile and outcome of patients with post-neonatal tetanus in a tertiary centre in south west Nigeria: any remarkable reduction in the scourge? Pan Afr Med J. 2015; 21: 254. Ref.: https://tinyurl.com/y2josntk 
7. Adegboye OA, Adeboye MAN, Anoba S. Childhood tetanus; Still a public health concern: A review of 95 case. Savannah Journal of Medical Research and Practice. 2012; 1. Ref.: https://tinyurl.com/y2lqvekv

8. Mondal T, Aneja S, Tyagi A, Kumar P, Sharma D. A study of childhood tetanus in post-neonatal age group in Delhi. Indian Pediatr. 1994; 31: 1369-1372. Ref.: https://tinyurl.com/y6oonnrz

9. Faulkner AE, MPH, Tejpratap SP, Tiwari. CDC; Manual for the Surveillance of vaccine preventable diseases: Tetanus, Chapter 14. Ref.: https://tinyurl.com/y4fnphuv

10. Wassilak SGF, Roper MH, Kretsinger K, Orenstein WA. Tetanus toxoid. In: Plotkin SA, Orenstein WA, Offit PA, eds. Vaccines fifth edition. Philadelphia: Saunders. 2012; 746-772.

11. CDC. Final 2015 reports of nationally notifiable infectious diseases and conditions. MMWR Morb Mortal Wkly Rep. 2016; 65: 1306-1321. Ref.: https://tinyurl.com/y3awd2sp

12. CSTE. Public health reporting and national notification for tetanus. CSTE position statements 09-ID63. Atlanta, GA: CSTE; 2010. 1-8. Ref.: https://tinyurl.com/y69vslvj

13. Oyedeji GA. Socio-economic and cultural background of hospitalised children in llesha. Nig J Paediatr. 1985; 12: 111-117. Ref.: https://tinyurl.com/y3wrx9rf

14. Oyedeji OA, Fadero F, Joel-Medewase F, Elemile P, Oyedeji GA. Trends in neonatal and post-neonata tetanus admissions at a Nigerian teaching hospital. J Infect Dev Ctries. 2012; 6: 847-853. Ref.: https://tinyurl.com/y6g2kp2a

15. Anah MU, Etuk IS, Ikpeme OE, Ntia HU, Ineji EO, et al. Post Neonatal Tetanus in Calabar, Nigeria: A 10 Year Review. Nigerian Medical Practitioner. 2009; 54. Ref.: https://tinyurl.com/y4p6yuxf

16. Alhaji MA, Akuhwa RT, Mustapha MG, Ashir GM, Mava Y, et al. Post-neonatal tetanus in University of Maiduguri Teaching Hospital, North-eastern Nigeria. Nig J Paediatr. 2013; 40: 154-157. Ref.: https://tinyurl.com/y34kzoft

17. Fatunde OJ, Familusi JB. Post-neonatal tetanus in Nigeria: The need for booster doses of tetanus toxoid. Nig J Paediatr. 2001; 28: 35-38. Ref.: https://tinyurl.com/y3g3lt54

18. Fortium $M$, Maine $N$, Mendy $M$, Hall A, George $M$, et al. Measles, polio and tetanus toxoid antibody levels in Gambian children aged 3-4years following routine vaccination. Trans R Soc Trop Med Hyg. 1995; 89: 326-329. Ref.: https://tinyurl.com/y3bdun6r

19. Cilia FG, Spenz DJR, Urbieta EM, Carcedo MA, Perez TE. Immunity against tetanus in Childhood. An Esp Pediatr. 1993: 38; 499-502. Ref.: https://tinyurl.com/yxeeatlp

20. Aboud S, Matre R, Lyamuya EF, Kristoffersen EK. Levels and avidity of antibodies to tetanus toxoid in children aged 1-15 years in Dar es Salaam and Bagamoyo, Tanzania. Ann Trop Paediatr. 2000; 20 313-322. Ref.: https://tinyurl.com/yxeeatlp

21. Yaguo ILE, Uchenwa-Onyenegecha TA. Tetanus in Nigeria: Is the end in sight? Greener J Med Sci. 2015; 5: 053-057. Ref.: https://tinyurl.com/y6lejyc8

22. Akuhwa RT, Alhaji MA, Bello MA, Bulus SG. Post-neonatal tetanus in Nguru, Yobe State, North-eastern Nigeria. Nig Med Pract. 2010; 57: 40-42. Ref.: https://tinyurl.com/yy8t29ze

23. Nte AR, Mayuku A, Oruamobo RS. Neonatal and post neonatal tetanus: the time to act is now. Nig J Paediatr. 2002; 29: 85.

24. Lambo JA, Anokye EA. Prognostic factors for mortality in neonatal tetanus: a systematic review and meta-analysis. Int J Infect Dis. 2013; 17: 1100-1110. Ref.: https://tinyurl.com/y6axfz5r

25. Gbadegesin RA, Adeyemo AA, Osinusi K. Childhood post-neonatal tetanus. Nig J Paediatr. 1996; 23 : 11-15. Ref.: https://tinyurl.com/y2l877kg 